\title{
DEVELOPMENT OF A LOW COST PPU FOR FEEP ELECTRIC PROPULSION USING COTS COMPONENTS
}

\author{
Bernhard Seifert, Alexander Reissner, David Jelem, Thomas Hörbe \\ FOTEC Forschungs- und Technologietransfer GmbH, seifert@fotec.at
}

\begin{abstract}
In the frame of the development of an electric-propulsion thruster for Micro- and Nanosatellites, FOTEC has put forward the in-house development of a low cost PPU, capable of driving the thruster with up to $10 \mathrm{kV}$ emitter and $-10 \mathrm{kV}$ extractor voltage. After 5 generations of development, the PPU currently used in a thruster testing and qualification campaign has achieved $85 \%$ total efficiency including high voltage multiplier stages and protection circuitry. The PPU includes the functionality of the step-up conversion for emitter and extractor, propellant heating and neutralizer-operation within a volume of $90 \times 94 \times 78 \mathrm{~mm}$, at a weight of less than $230 \mathrm{~g}$ and a total cost in production of less than $€ 1,000$. This low cost approach using COTS components is targeting constellations and mega-constellations and is certainly the other extreme compared to the conventional design approach for spacecraft PPUs. In the light of the ongoing discussions of a change in the philosophy of designing spacecraft, going from fail-safe components to a "mass production" strategy which aims for fail-safety by redundancy. This paper also gives a starting point for the discussion on how a possible tradeoff between cost and reliability can be achieved.
\end{abstract}

\section{Introduction}

For several years, FOTEC has developed the $\mathrm{mN}$ FEEP thruster to be used in future ESA missions [1]. This thruster can provide highly accurate thrust ranging from $1 \mu \mathrm{N}$ to above $1 \mathrm{mN}$ [2]. It allows large satellites to control their position with an unprecedented accuracy enabling e.g. formation flight of scientific spacecraft [3]. In order to emit ions at an $\mathrm{I}_{\mathrm{sp}}$ of up to 5,000 $\mathrm{s}$ at a dynamic thrust range from $1 \mu \mathrm{N}$ to $1 \mathrm{mN}$, a so called crown emitter is being used, that has been developed by FOTEC for the ESA NGGM mission [4, 5, 6, 7]. This emitter was initially developed to enable fixed formation flight missions and therefore combines a large thrust range with outstanding accuracy (see Figure 1).

As the need of a propulsion system for micro- and nano-satellites became an urgent matter, it has been realized, that the thrust level provided by this mN-FEEP thruster already allows significant increase of the mission range of such satellites. The high $\mathrm{I}_{\mathrm{sp}}$ on the other hand allows for very high $\Delta v$ maneuvers at high propellant utilization efficiency.

Keeping the emitter in the configuration for the NGGM mission, the housing of the thruster has entirely been re-designed in order to fit into a standard CubeSat structure [8]. In parallel, a PPU has been developed and been integrated into the thruster module (see Figure 2). The result of this redesign is the new IFM nano thruster module with the particular advantage that no miniaturization of the emitter itself was necessary. The thruster module, therefore, can build on an extensive development history that has started long before the present application has emerged. The result is a highly performant compact thruster module, that includes all subsystem from the thruster and PPU up to the propellant and neutralizer in less than $1 \mathrm{U}$ at less than $1 \mathrm{~kg}$.

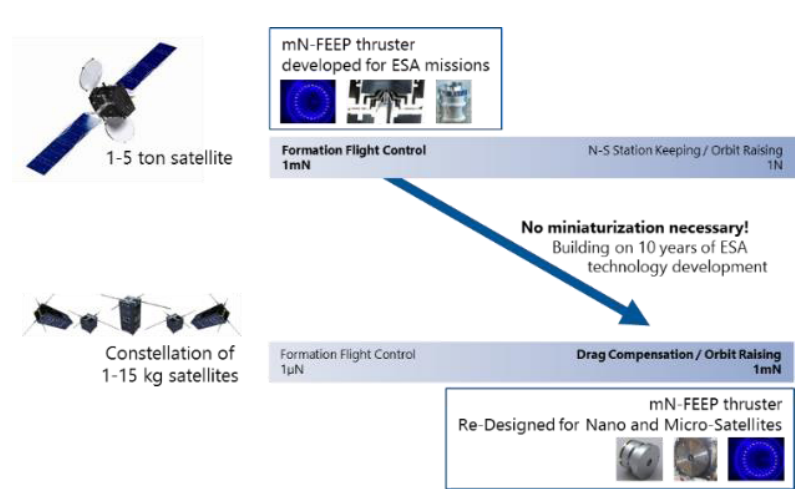

Figure 1 Evolution of the IFM nano thruster from the $m N$-FEEP thruster developed for ESA.

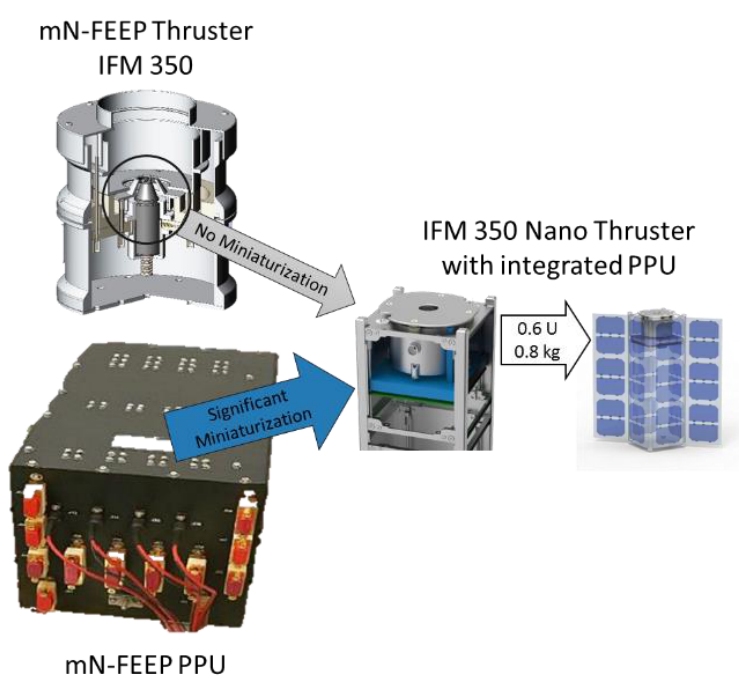

Figure 2 Development of the IFM nano thruster from existing technology. 


\section{The Indium FEEP Technology - State of the art and achievements from previous developments}

Field emission is an effect which is closely tied to the presence of strong electric fields. In practice, this means that the fundamental structure on which field emission takes place is shaped like a needle, due to the field-enhancing effect at its tip. An important application of this effect is the so-called Liquid Metal Ion Source (LMIS), because it uses the process of field emission to ionize a thin film of liquid metal covering the needle which is biased towards several $\mathrm{kV}$ with respect to the counter electrode (extractor). The thusly created ions are then accelerated by the strong electric fields and can be used for ion implantation in semiconductor industry or for micromachining with a focused ion beam (FIB).

The Department of Aerospace Engineering at FOTEC (the former department Space Propulsion and Advanced Concepts at the Austrian Institute of Technology, AIT) has a long and successful heritage in manufacturing LMIS for space. They have been used for mass spectrometer (for example on ROSETTA) or for spacecraft potential control (for example on the NASA mission MMS). Up to date, FOTEC is the only supplier worldwide for LMIS with flight heritage (see Table 1).

\begin{tabular}{|c|c|c|c|}
\hline Experiment & Function & $\begin{array}{l}\text { Spacecraft / } \\
\text { No. of LMIS }\end{array}$ & Operation Time \\
\hline LOGION & $\begin{array}{l}\text { Test of LMIS in } \mu- \\
\text { Gravity }\end{array}$ & MIR / 1 & $24 \mathrm{~h}(1991)$ \\
\hline MIGMAS/A & Mass Spectrometer & MIR / 1 & $120 \mathrm{~h}(1991-94)$ \\
\hline EFE-IE & $\begin{array}{l}\text { S/C Potential Con- } \\
\text { trol }\end{array}$ & GEOTAIL / 8 & 600 h (1992 -) \\
\hline PCD & $\begin{array}{l}\text { S/C Potential Con- } \\
\text { trol }\end{array}$ & $\begin{array}{l}\text { EQUATOR-S / } \\
8\end{array}$ & $250 \mathrm{~h} \mathrm{(1998)}$ \\
\hline ASPOC & $\begin{array}{l}\text { S/C Potential Con- } \\
\text { trol }\end{array}$ & CLUSTER / 32 & $\begin{array}{l}\text { Ariane } 5 \text { launch failure } \\
1996 \text { Still operational } \\
\text { after crash }\end{array}$ \\
\hline ASPOC-II & $\begin{array}{l}\text { S/C Potential Con- } \\
\text { trol }\end{array}$ & $\begin{array}{l}\text { CLUSTER-II / } \\
32\end{array}$ & 6516 (since 2000 ) \\
\hline COSIMA & Mass Spectrometer & ROSETTA / 2 & $\begin{array}{l}\text { Fully Operational, Ex- } \\
\text { periment Ongoing }\end{array}$ \\
\hline$\overline{\text { ASPOC/DSP }}$ & $\begin{array}{l}\text { S/C Potential Con- } \\
\text { trol }\end{array}$ & DoubleStar / 4 & 8979 h $(2004-2007)$ \\
\hline $\begin{array}{l}\text { MMS } \\
\text { ASPOC }\end{array}$ & $\begin{array}{l}\text { S/C Potential Con- } \\
\text { trol }\end{array}$ & MMS / 32 & $\begin{array}{l}\text { Commissioned suc- } \\
\text { cessfully in } 2015\end{array}$ \\
\hline
\end{tabular}

Table 1 Flight heritage of FOTEC LMIS.

This principle of generating positive ions and accelerating them by the very same field can also be used to generate thrust. When a liquid metal ion source is used in this way, it is termed Field Emission Electric Propulsion (FEEP).

Since the number of ions and their energy can conveniently be controlled by the applied voltage levels, outstanding thrust accuracy can be achieved. The main advantage of using FEEP thrusters lies in their capability to produce thrust from the sub- $\mu \mathrm{N}$ level up to several tens of $\mu \mathrm{N}$ per needle.

For more than 15 years, research has been carried out to use this technology for generation of ultra-precise thrust in the $\mu \mathrm{N}$-range suitable for formation flights of multiple spacecraft. The FEEP technology has been put forward in ESA's Basic Technology Research Program and in the frame of early preparatory studies for the Next Generation Gravity Mission (NGGM).
In this environment, the so-called porous Tungsten crown emitter has been developed, which employs 28 needles for field emission. Apart from the multiple emission sites, the most important new feature was the porous Tungsten matrix which enables internal flow of the liquid metal (similar to a capillary type emitter) to a very sharp tip (similar to a solid needle). It therefore combines the advantages of both, the capillary emitter and the solid needle.

Another key feature of the porous Tungsten crown emitters is the rapid manufacturing method from using micro powder injection molding. In this process, a mixture of Tungsten powder and binding polymer is injected into the mold and subsequently sintered to achieve final hardness and purity. In the course of this procedure, the structure becomes porous and facilitates flow of propellant through its volume.
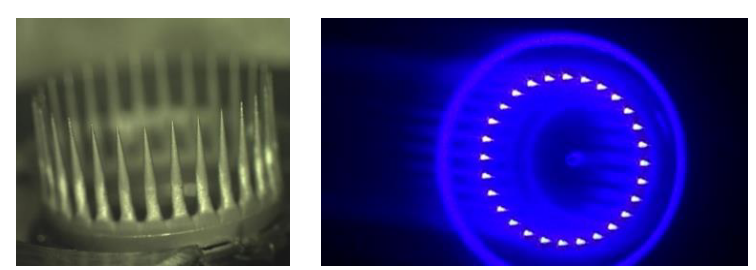

Figure 3 Porous tungsten crown emitter after wetting with Indium (left), high-thrust operation (right).

Depending on the voltage applied to the crown emitter, a certain number of needles is actually emitting ions. As indicated in the picture above at high thrust levels, almost all needles are contributing to the total current whereas at low thrust levels only a couple of needles, whose electrical impedance is lowest, is emitting ions. This behavior allows operation at a thrust level ranging from few $\mu \mathrm{N}$ up to several $\mathrm{mN}$.

In Figure 4 the typical performance of a 28 -needle porous crown emitter, operated at $3 \mathrm{~mA}$ ion current, is shown. One recognizes the ability to shift the extractor voltage which allows a trade-off between high specific impulse (low extractor voltage) and high thrust-to-power operation (high extractor voltage). The I-V characteristic of this emitter is shown in Figure 5.

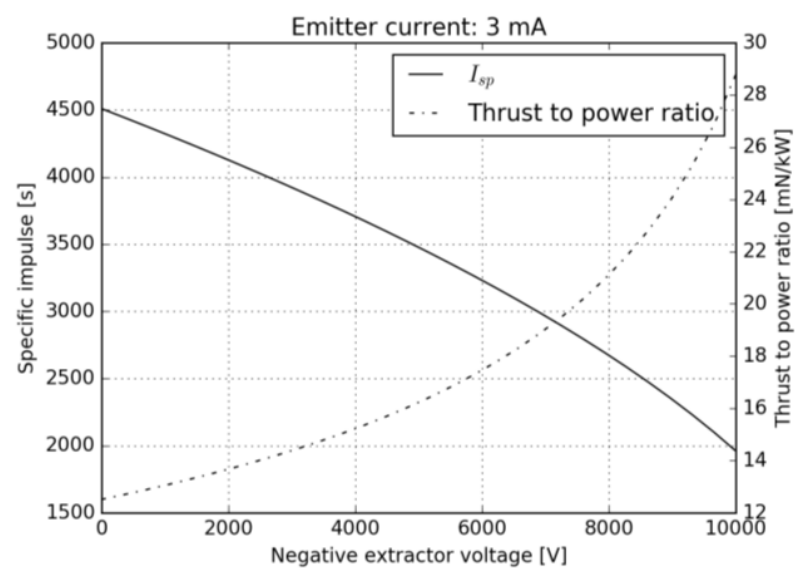

Figure 4 Typical performance of a 28-needle porous crown emitter. 


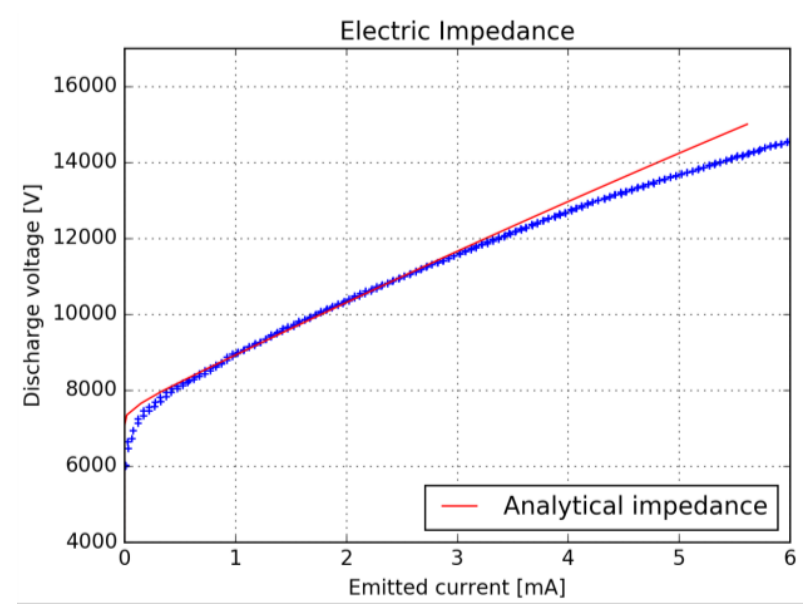

Figure 5 Measured I-V characteristic of porous Tungsten crown emitter with theoretical model [9].

Extensive testing of these emitters includes voltage/current characteristic measurements, direct thrust measurements, characterization of the start-up behavior, determination of the mass efficiency and a lifetime test.

At the time of finalization of this paper the ongoing lifetime test has demonstrated more than $12,000 \mathrm{~h}$ of operation without detectable performance degradation, targeting $20.000 \mathrm{~h}$ and more [10].

\section{Thruster Design Concept}

The following thruster design has been established in order to accommodate the present emitter technology on a micro- or nano-satellite (see Figure 6).

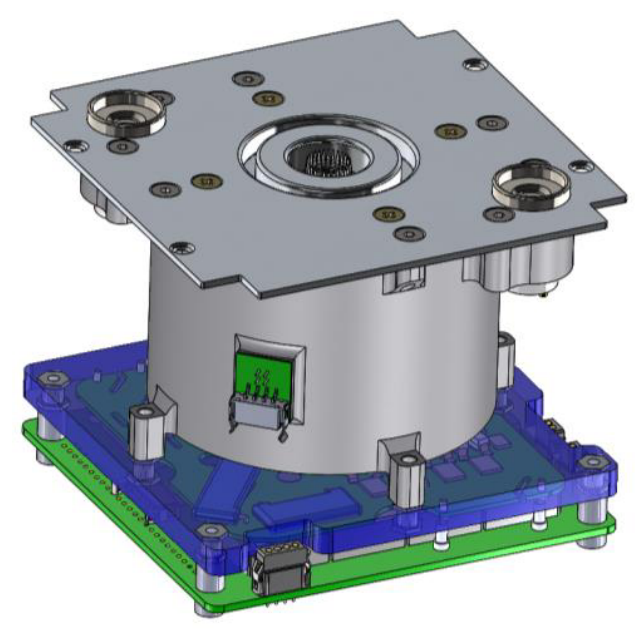

Figure 6 Simplified design of the IFM nano thruster module. It consists of the top plate with crown emitter and extractor ring, the housing, the high voltage PPU (blue) and the low voltage PPU (bottom).

Each module includes the emitter itself, the propellant with heater, the power processing unit, the high voltage multipliers and a two redundant neutralizers. The thruster uses either pure Indium or an alloy of Indium and Gallium as propellant which are both solid at room temperature. When the thruster shall be operated in orbit, the pro- pellant is heated above its melting point and becomes liquid. Avoiding any liquid and reactive propellants as well as pressurized tanks during integration and launch significantly simplifies corresponding procedures and regulations.

Electrical interfaces between the IFM nano thruster module and the spacecraft are reduced to a low voltage power bus $(12 \mathrm{~V})$ and a digital communication interface. Auxiliary voltages are generated internally from the supply voltage.

Table 2 shows the key parameters of the IFM nano thruster module.

\begin{tabular}{ll}
\hline Parameter & Value \\
\hline Dynamic thrust range & $1 \mu \mathrm{N}$ to $1 \mathrm{mN}$ \\
\hline Nominal thrust & $350 \mu \mathrm{N}$ \\
\hline Specific impulse & 2,000 to $4,500 \mathrm{~s}$ \\
\hline Propellant mass & 30 to $250 \mathrm{~g}$ \\
\hline Total impulse & more than $5,000 \mathrm{Ns}$ \\
\hline Power at nominal thrust & $31 \mathrm{~W}$ incl. neutralizer \\
\hline Outside dimensions & $94 \times 90 \times 78 \mathrm{~mm}$ \\
\hline Mass (dry / wet) & $640 / 870 \mathrm{~g}$ \\
\hline
\end{tabular}

Table 2 Key performance figures of the IFM nano thruster module.

\section{System Overview}

For proper operation of the FEEP porous crown emitter in the IFM nano thruster module, the integrated PPU has to provide several controllable outputs:

- Positive DC high voltage generation for the FEEP emitter: 0 to $10 \mathrm{kV}, 0$ to $3 \mathrm{~mA}$

- Negative DC high voltage generation for the extractor electrode: 0 to $-10 \mathrm{kV}, 0$ to $-300 \mu \mathrm{A}$

- Positive DC low voltage generation for the propellant heater: 0 to $20 \mathrm{~W}$

- AC low voltage generation for each of the two neutralizers: 0 to $3 \mathrm{~W}$

- Negative high voltage biasing of both neutralizers: fixed to $-200 \mathrm{~V}$

The PPU is operated at the nominal voltage of $12 \mathrm{~V}$ which has to be provided by the spacecraft power sourcing unit (PSU). The given voltage and current figures are maximum values which are only reached at maximum thrust levels. For lower thrust requirements or at lower specific impulse levels, these figures can be significantly lower.

The conversion efficiency is crucial for long-term operation since no active cooling means like active heat pipes or levers can be implemented in the small size of the module. A prototype PPU has been developed with a maximum total deliverable power of $40 \mathrm{~W}$, at the final average efficiency of $85 \%$, the total heat losses are therefore below $6 \mathrm{~W}$. During the development of the PPU, the focus is laid on efficiency optimizations, reliability and controllability.

For proper operation, the PPU continuously monitors several temperatures across the module, voltages and currents. Therefore, remote diagnostics enable the detection 
of any malfunctioning during operation.

\section{High Voltage Generation}

In order to keep the output-to-input ratio of both high voltage sections for the emitter and extractor as low as possible, a highly efficient pulse width modulation (PWM) controlled, fixed frequency, full-bridge topology was chosen. The bridge voltage corresponds to the nominal supply voltage and the optimum switching frequency was designed to be $60 \mathrm{kHz}$. Commercially available cold cathode fluorescent lamp (CCFL) small-size transformers are being utilized to generate output voltages of up to $1200 \mathrm{~V}$ (ratio of 1:100).

A Villard type diode-capacitor multiplier ladder circuit is connected to generate the desired output voltage of up to $10 \mathrm{kV}$ for the emitter and up to $-10 \mathrm{kV}$ for the extractor respectively. The multiplier circuitry is located on a separate board (high voltage PPU) to avoid any spark-overs or creeping currents which might occur due to miniaturization of the design. In addition, the high voltage PPU is potted with STYCAST FT-2850 low outgassing epoxy resin for additional protection against coronal discharges. In Figure 7 the most current design of the low voltage PPU is shown.

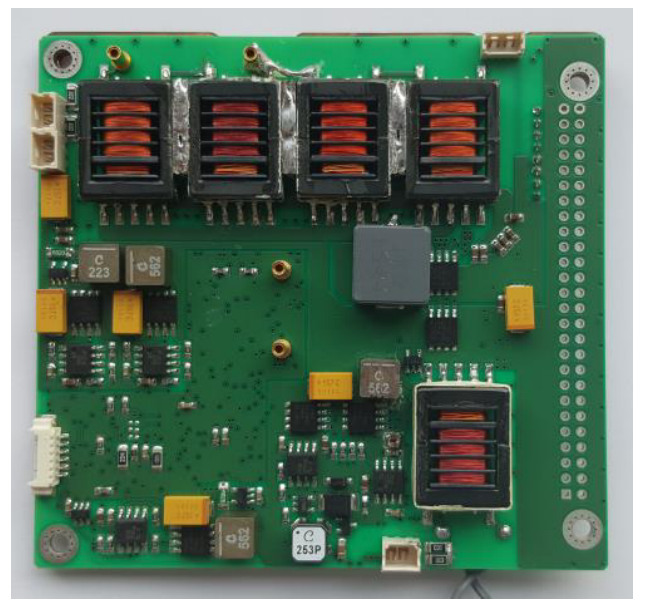

Figure 7 Prototype of low voltage PPU suitable for standard CubeSat bus.

Both, the emitter and the extractor can be individually operated in current-, voltage- or power-control mode. Since the power of the emitter section is up to $25 \mathrm{~W}$, four CCFL transformers are used in parallel to share the load. For the extractor circuitry a single transformer is sufficient.

For nominal operation the extractor is voltage controlled and set to a fixed voltage. The emitter is current controlled to control the required thrust. The theoretical thrust is internally estimated and a feed-back loop controls the power supplies to maintain the commanded thrust. In case of erroneous voltage or current feedback measurements, both full bridges can be duty-cycle controlled.

\section{Heater and Temperature Control}

The heater power section, used to melt the propellant, uses a half-bridge topology with attached LC-filtering to maintain highest efficiency at low AC ripple. The heater itself is comprises of high-temperature resistance wire encapsulated in Aluminum oxide ceramic. During hotstandby the heater has to keep the propellant liquid, which allows instantaneous thruster operation. For Indium propellant the reservoir temperature is being controlled to $180^{\circ} \mathrm{C}$ and for Indium-Gallium alloy $100{ }^{\circ} \mathrm{C}$ is sufficient. If the heater is disabled, the propellant reservoir cools down to ambient temperature and it takes up to 60 minutes to heat up the reservoir again before the thruster itself can be re-enabled.

Since the emitter and the attached propellant reservoir is kept at up to $10 \mathrm{kV}$ during operation, accurate temperature sensing is challenging. The PPU therefore uses a contact-less so called thermopile which uses the pyroelectric effect in conjunction with absorption of heat radiation from the reservoir. Alternatively, electrically insulated temperature sensors, such as thermocouples, can be used. However, tests have shown significant measurement errors since the insulator is acting as a thermal barrier as well.

In Figure 8 the temperature profile during heat-up is shown. The melting point of pure Indium at $156.6^{\circ} \mathrm{C}$ can be observed which is used for additional verification of the thermal calibration.

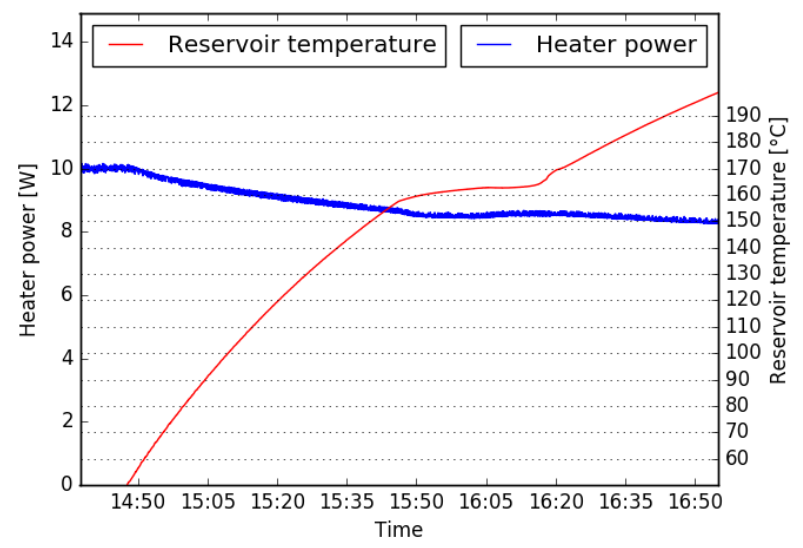

Figure 8 Temperature profile of the reservoir during controlled heat-up.

\section{Neutralizer and Spacecraft Charging}

Since ions are expelled at a total current of up to 3 $\mathrm{mA}$, the FEEP thruster module needs means to balance spacecraft charging. This is achieved by the use of two cold-redundant electron sources acting as neutralizers. Such an electron source consists of a Tantalum disc which is heated up to $2,200 \mathrm{~K}$ and biased to $-200 \mathrm{~V}$. The electrons are expelled when the spacecraft is negatively charged whereas the active biasing is required to overcome the negative potential generated by the extractor ring electrode. Once electrons have left the neutralizer, they will be pulled towards the positive potential of the ion plume. (see Figure 9). The PPU is able to measure 
this charge balancing current and it can automatically control the heating power of the neutralizers.

The neutralizer discs are connected to the PWM output of a half bridge via an inductor and decoupling / pumping capacitors. This allows biasing the neutralizer discs and allows measurement of the charge balancing current.

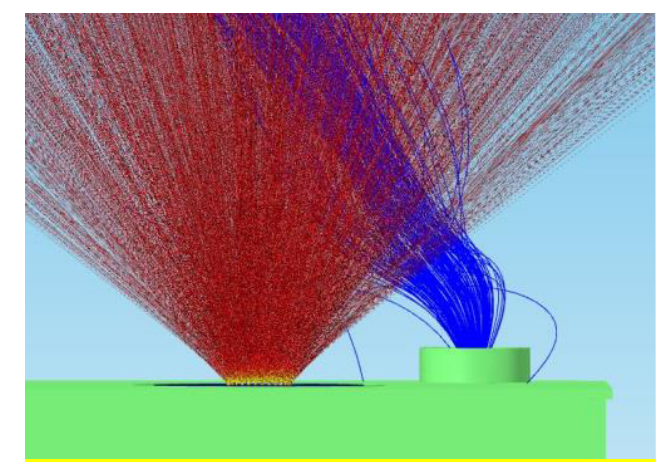

Figure 9 Electrons (blue) being pulled into the emitted ion plume (red).

\section{Communication and Software}

The IFM nano thruster module is based on an 8-bit Atmel AVR8 type microcontroller and uses a $3.3 \mathrm{~V}$ digital communication interface (UART, $\mathrm{I}^{2} \mathrm{C}$ or RS-422). It provides a memory map being read and written by the onboard computer (OBC) to read the status or control the thruster respectively. Each message uses an 8-bit cyclic redundancy check (CRC8) checksum which protects against bit flips on the communication line.

Firmware updates are supported which allows in-orbit bug-fixes or adaptation of the software, if required. Since the microcontroller provides in-system programming capability, no additional interface to the $\mathrm{OBC}$ is required.

Crucial non-volatile values, such as the calibration factor of the thermopile, are stored in electrically erasable programmable read-only memory (EEPROM) section of the microcontroller multiple times and are auto-corrected during read-out with voters.

Software-configurable fuses are implemented to detect over-voltage, over-current or over-temperature conditions. In case of sensor malfunction or analog-digital converter (ADC) failure, they can individually be disabled during operation.

\section{System Efficiency}

Any power losses of the PPU need to dissipated by the spacecraft structure in order to prevent overheating of the PCBs and populated components. Since the PCB mostly consists of FR4 glass-fiber enhanced epoxy resin, the thermal conductivity is rather low compared to Aluminum or Copper. Preliminary tests have revealed that the heat gradient through the PCB from the transformers to the interface connections at the corners is too large to keep the PPU continuously below $85^{\circ} \mathrm{C}$ at full-power operation (see Figure 10).
Thermal management is crucial to ensure operation under varying thermal environments and interface temperatures. Therefore, a solid Aluminum heat spreader was developed to guide the heat flux from the transformers (which are the major source of power losses) through cut-outs in the PCB directly to the rear side of the IFM nano thruster module and further to the interface of the spacecraft. Threads allow tight connection and thus good thermal contact to the spacecraft bus (see Figure 10). Additionally, in order to increase the effective contact surface area, thin Indium foil washers were used at all connection points along the heat path to prevent temperature drops.

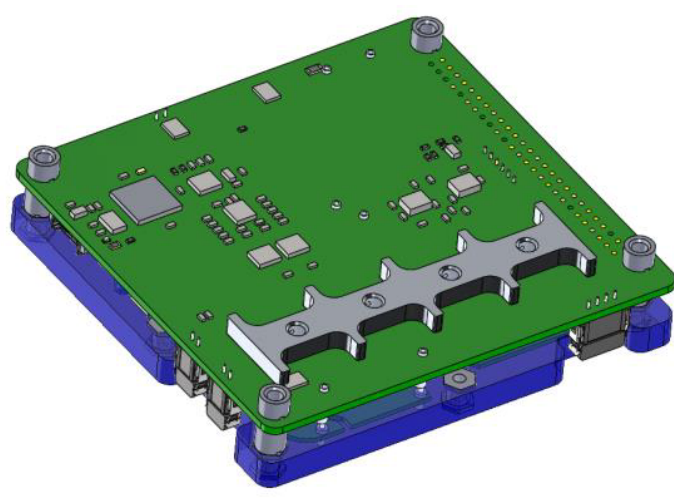

Figure 10 Solid Aluminum heat spreader at the rear side of the low voltage PPU.

First FEM simulations and experimental tests have shown significant improvements and confirm the design. The PPU could continuously be operated at nominal output power at an interface temperature of $40{ }^{\circ} \mathrm{C}$. The following thermal image was taken from a setup where only the two right transformers were in thermal contact with the heat spreader (see Figure 11, white circle). One can recognize the significantly lower temperature of the ferrite cores compared to the two left transformers.

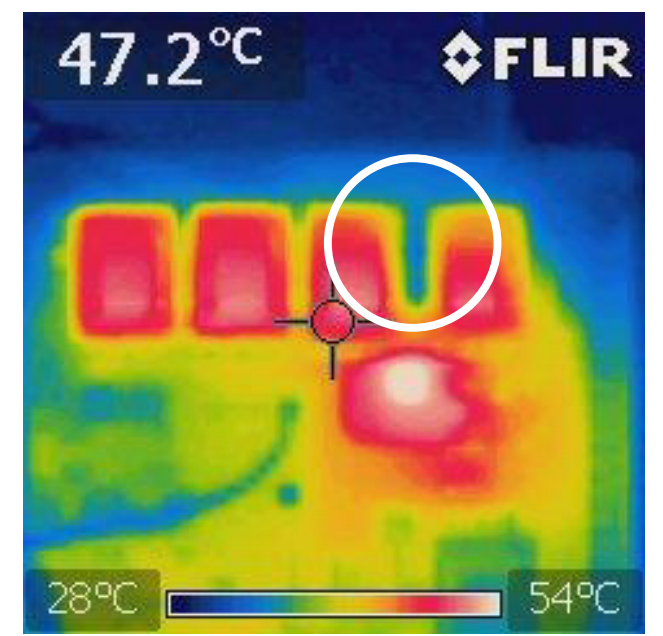

Figure 11 Temperature distribution of the low voltage PPU at high power operation in air.

The PPU was tested when fully integrated into an engineering model and subjected to typical electrical load 
conditions gathered from known I-V FEEP emitter characteristic. In the following test, the temperature of reservoir was being held constant at $170{ }^{\circ} \mathrm{C}$ and the emitter was controlled from 0 to $20 \mathrm{~W}$ output power. A $4 \mathrm{M} \Omega$ high voltage power resistor was being used to load its output (see Figure 12).

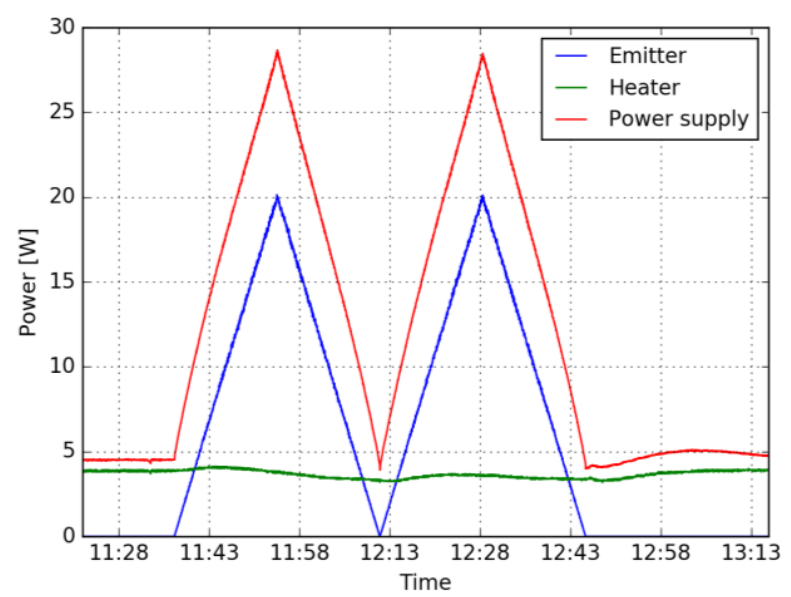

Figure 12 High output power test with temperature controlled heater (green), emitter power (blue) and total input power (red).

At emitter output power of $20 \mathrm{~W}$ and heater output power of $4 \mathrm{~W}$ the total input power was measured to be $28 \mathrm{~W}$ which corresponds to ca. $85 \%$ overall system efficiency. One recognizes that less heater power is required when the emitter is operated at high power.

As the PPU is optimized for nominal output power and therefore, the relative losses increase at lower emitter power levels. The load-independent constant power losses were found to be $0.18 \mathrm{~W}$ and the output power dependent losses increase almost linearly with the output power (see Figure 13).

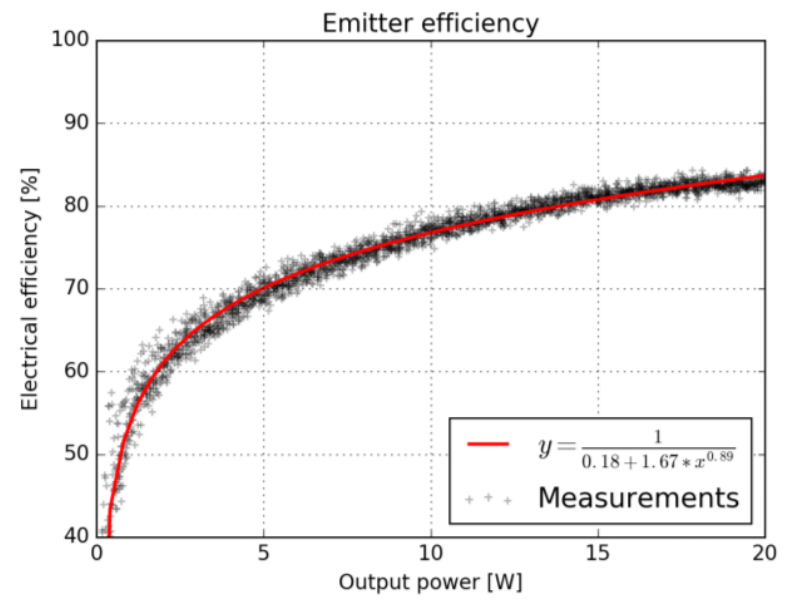

Figure 13 Electrical emitter efficiency vs. emitter output power. The constant losses reduce the relative efficiency at low emitter power levels.

The heater efficiency shows similar behavior and was found to be $87 \%$ for a typical output power of $4 \mathrm{~W}$ which is required to keep the reservoir at $175^{\circ} \mathrm{C}$ (see Figure 14).
At higher output power levels, the efficiency reaches more than $97 \%$.

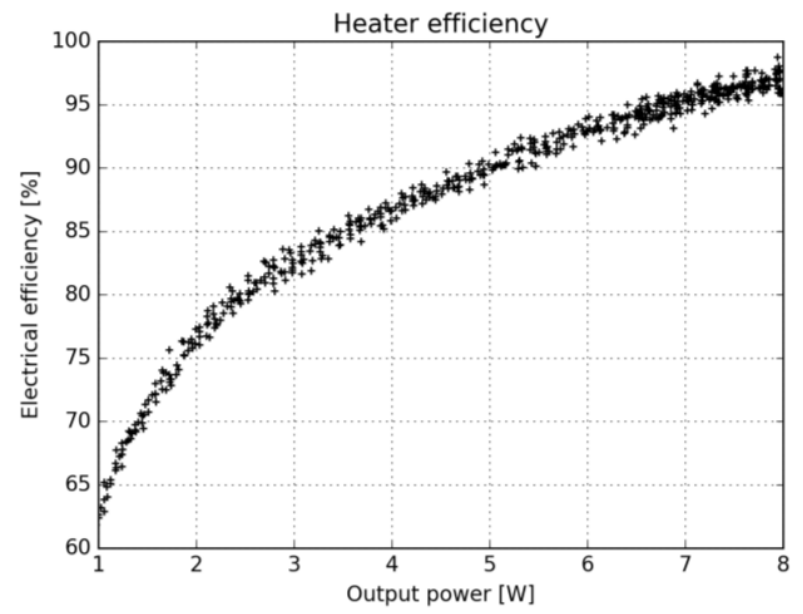

Figure 14 Electrical heater efficiency vs. heater output power. The constant losses reduce the relative efficiency at low heater power levels.

For system engineers, being mainly interested in the generated thrust for a given input power, the following chart is important. As already summarized in Table 2 the nominal thrust level of $300 \mu \mathrm{N}$ can be achieved at an input power of $31 \mathrm{~W}$. This figure includes all electrical efficiency losses, the required heater power to maintain the reservoir temperature and the power to operate the neutralizer to compensate for spacecraft charging (see Figure 15).

The constant power use of the PPU is $7 \mathrm{~W}$ even when no thrust is generated. This results from the heater power $(4 \mathrm{~W})$ and the neutralizer power $(3 \mathrm{~W})$.

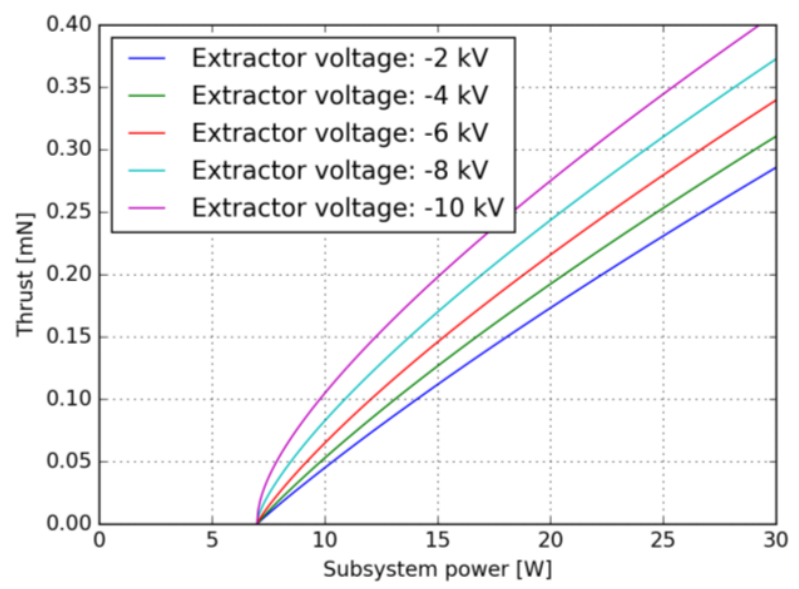

Figure 15 System power requirements for different thrust levels at various extractor voltages.

\section{In Orbit Demonstration}

FOTEC is currently building flight modules of the IFM Nano thruster to be launched in Q3 2017 on a commercial platform. The spacecraft will accommodate the IFM Nano thruster module in a seven module configuration. A common housing as seen in Figure 16 will be 
placed inside a 15 -inch separation ring being used to detach the spacecraft from the launcher. Multiple units of the IFM nano thruster modules can be combined and be operated in parallel to provide higher thrust levels without degradation of system efficiency. By the use of seven modules an overall thrust of more than $2 \mathrm{mN}$ can be achieved at an input power below $200 \mathrm{~W}$. This takes into account the reduced heater power and the reduced number of neutralizers to perform charge balancing.
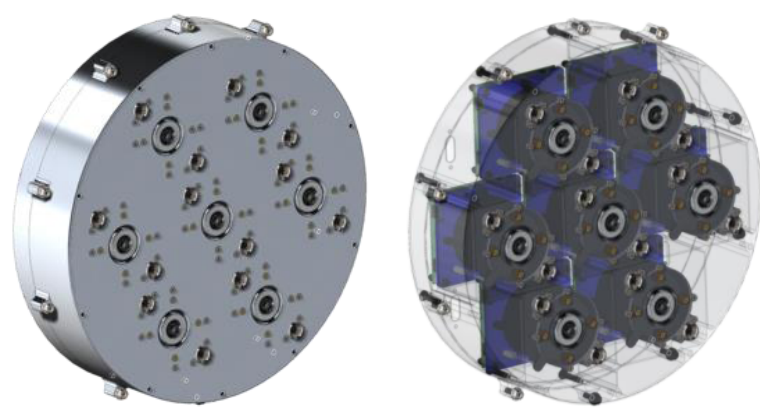

Figure 16 Propulsion module being placed inside the separation ring. It consists of seven independent IFM Nano thruster modules.

\section{Conclusions}

The IFM nano thruster module offers a unique continuously scalable $\mathrm{I}_{\mathrm{sp}}$ range combined with high electrical efficiency, compact dimensions and ultra-high propellant density. The herein presented PPU solely consists of COTS components and is capable of powering and controlling all necessary subsystems and supports a large portion of the operational envelope a FEEP emitter can offer with regard to $\mathrm{I}_{\mathrm{sp}}$ and thrust.

It was shown that the PPU sustained a test campaign under realistic load conditions such as thermal vacuum or vibrational tests. The PPU showed outstanding electric efficiency compared to competitors' high voltage generators. Ongoing developments of the PPU will extend the accessible thrust and $\mathrm{I}_{\mathrm{sp}}$ levels even further which, in turn, increases the range of missions profiles for nano- and micro-satellites.

As the trend towards electric propulsion is strongly emerging, FOTEC is well positioned as the only supplier of integrated FEEP propulsion systems.

\section{References}

[1] I. Vasiljevich, M. Tajmar, W. Grienauer, F. Plesescu, N. Buldrini, J. Gonzalez del Amo, B. Carnicero Domunguez, and M. Betto, Development of an Indium mN-FEEP Thruster, 2008

[2] A. Reissner, N. Buldrini, B. Seifert, F. Plesescu, C. Scharlemann, and J. G. del Amo, $m N-F E E P$ Thruster Module Design and Preliminary Performance Testing, presented at the 33rd International Electric Propulsion Conference, Washington, D.C., USA, 2013

[3] A. Reissner, N. Buldrini, B. Seifert, and F. Plesescu, Detailed Performance Characterization of the $m N-F E E P$ Thruster, presented at the Space Propulsion 2014, Cologne, Germany, 2014

[4] I. Vasiljevich, N. Buldrini, F. Plesescu, M. Tajmar, M. Betto, and J. Gonzalez del Amo, Porous tungsten crown multi-emitter testing programme using three different grain sizes and sintering procedures, in Proceeding of the International Electric Propulsion Conference, Wiesbaden, Germany, 2011

[5] I. Vasiljevich, N. Buldrini, F. Plesescu, M. Tajmar, M. Betto, and J. del Amo, Consolidation of milliNewton FEEP Thruster Technology based on Porous Tungsten Multiemitters, 2011

[6] M. Tajmar, I. Vasiljevich, and W. Grienauer, High current liquid metal ion source using porous tungsten multiemitters, Ultramicroscopy, vol. 111, no. 1, pp. 1-4, Dec. 2010

[7] M. Tajmar, I. Vasiljevich, F. Plesescu, W. Grienauer, N. Buldrini, M. Betto, and J. G. del Amo, Development of a porous tungsten mN FEEP thruster, in Proceedings of the Space Propulsion Conference, San Sebastian, 2010.

[8] California Polytechnic State University, CubeSat Design Specification, Rev. 12

[9] G. L. R. Mair, Theoretical determination of current-voltage curves for liquid metal ion sources, J. Phys. D: Appl. Phys., 1984

[10] A. Reissner, N. Buldrini, B. Seifert, F. Plesescu, and T. Hörbe, Lifetime Testing of the $m N-F E E P$ Thruster, presented at the Space Propulsion 2016, Rome, Italy, 2016 